\title{
After The Revolution: Twenty Years of Portuguese Literature, 1974-1994. Editado por: Helena Kaufman e Anna Klobucka. Lewisburg: Bucknell University Press; London: Associated University Press, 1997. 252 pp.
}

Marcus Vinicius de Freitas Universidade Federal de Minas Gerais

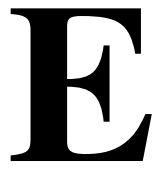

m um artigo publicado em 1983 na revista Prelo,

Eduardo

Lourenço construía uma indagação sobre identidade nacional que colocava o problema de maneira extrema-mente aguda. O nome do artigo, "Crise de identidade ou ressaca imperial?', trazia em si mesmo a marca da fina argumentação de Lourenço. A pergunta se relacionava, àquela altura, com questões que haviam surgido após a Revolução dos Cravos, e que em suma formavam uma indagação sobre como compreender a perda do império. Poderíamos igualmente ler a pergunta de Lourenço como sendo: crise pós-utópica ou ainda modernidade? Respondendo à própria questão, Lourenço descartava a existência de qualquer crise de identidade e propunha, ao contrário, o conceito de hiperidentidade, o qual enfatizava a continuidade histórica entre o Portugal pós-revolucionário e cinco séculos de permanente demanda por mudanças. Em outras palavras, do ponto de vista de Eduardo Lourenço a revolução de 1974 representava apenas mais um elo na cadeia de uma ainda viva "estética moderna da ruptura”, para usar as palavras de Octavio Paz. Helena Kaufman e Anna Klobucka, ao contrário, na introdução de After The Revolution: Twenty Years of Portuguese 
Literature, 1974-1994, afirmam que a revolução sinalizaria o fim da modernidade em Portugal, e sua conseqüente substituição por uma crise ideológica pós-moderna. Essa afirmação é entretanto muito ambígüa, e a ambigüidade percorre todo o livro organizado por Kaufman e Klobucka.

\section{Coleção de 10 ensaios} críticos, escritos por 11 autores, o livro cobre as duas últimas décadas da literatura portuguesa, passando pelos gêneros da poesia, do drama e do ensaio, mas devotando especial atenção ao romance, cujas análises ocupam, intencionalmente, metade do livro. Durante os últimos vinte anos, a produção de romances não foi necessariamente maior do que a de outros gêneros, mas claramente comandou a atenção dos críticos, certamente porque $\mathrm{a}$ análise do romance pode melhor expressar as obsessões dos estudos culturais, tais como a ênfase em questões antropológicas, as análises baseadas em gênero sexual e etnia, além das agendas políticas. Ao trazer para o leitor o leque dessas estratégias de análise, o livro de Kaufman e Klobucka está, para bem ou para mal, perfeitamente em dia com a moda.
As editoras dividiram o livro em três partes. Primeiramente uma Introdução, integrada pelo artigo de sua autoria, intitulado "Politics and Culture in Postrevolutionary Portugal", e por "State and Society in Portugal", da autoria de Boaventura de Sousa Santos. A seção central, Overviews (Visões Gerais), apresenta Fernando Martinho, José de Oliveira Barata e Onésimo Almeida discutindo poesia, drama e ensaio, respectivamente. Finalmente, a terceira e maior seção, Analysis, incorpora cinco visões sobre a ficção portuguesa. Essa parte inclui um texto de Helena Kaufman e José Ornelas sobre as relações entre história e ficção; um polêmico artigo de Ellen Sapega sobre identidade nacional; a discussão de Phillis Peres sobre as conseqüências narrativas e culturais da perda do império; e finalmente dois trabalhos sobre escrita feminina e feminista, de Isabel Allegro Magalhães e Ana Paula Ferreira, respectivamente.

A partir de uma ênfase nas teorias pós-modernas, as editoras compreendem Portugal como sendo um país pós-utópico. Entretanto, a estética da mudança 
e da ruptura possui ainda grande apelo para as autoras, e sobretudo aí reside a ambigüidade que percorre todo o livro. Se por um lado elas dizem que a principal característica da narrativa portuguesa pós-1974 constitui "...its centrality in the creation of the new national consciousness altered by the postrevolutionary (and syntomatically, postmodern) crisis of ideologies" (p. 27), por outro elas se contradizem, ao afirmar: "Signifying change and rupture, with implications still to be resolved, the 1974 revolution informs explicitly and implicitly all majors themes and issues discussed in this volume" (p.26).

Essa ambivalência em usar, por um lado, o aparato crítico dos estudos culturais e, por outro, basear-se no conceito de revolução cria claramente um desbalanceamento no livro. Poderse-ia dizer, porém, que o livro mais não faz do que coerentemente espelhar duas contradições maiores: a) a contradição interna da "condição pós-moderna", que se caracteriza, ao mesmo tempo, por um processo de desterritorialização dos discursos hegemônicos, das fronteiras e das identidades, e por sua reterritorialização em novos discursos de autoridade, fronteiras demarcadas e agendas políticoideológicas; b) a contradição própria de Portugal, visto enquanto um país moderno numa era pósmoderna, ou seja, a contradição interna de um país "semiperiférico", para usar os termos de Boaventura de Sousa Santos. As duas contradições podem até ser verdadeiras. As editoras, entretanto, não as assumem como pontos de discussão. Mais do que isso, elas meramente se deixam levar por aquelas contradições.

Curiosamente, Sousa Santos, que nada fala de literatura em seu artigo, é o autor que recebe a maior atenção por parte das editoras. Elas justificam sua escolha de um cientista social para ser o autor do artigo de fundo do livro com base no fato de que, para compreender as transformações do Portugal pós-revolucionário, "...one has to engage in an interdisciplinary research emcompassing the historical and synchronic, the economic and social, the political and cultural" (p.26). Apesar do mérito de seu argumento, elas simplesmente ignoram a primazia da literatura 
(afinal esse parecia ser o assunto do livro), e substituem-na por problemas antropológicos, atitude que deriva sobretudo de seu ponto de vista determinado pelos estudos culturais. Dos cinco artigos sobre o gênero do romance, dois são sobre escrita de mulheres, o que claramente superestima um ponto de vista restrito. Os três outros artigos procuram desconstruir velhas noções de história, ficção e representação, e igualmente discutem conceitos de espaço e identidade nacionais. Todos esses artigos seguem o mesmo bordão dos estudos culturais. Ellen Sapega, no entanto, produziu um ensaio muito interessante, que procura discutir as fronteiras entre moderno e pós-moderno no Portugal de hoje. Sua polêmica com Onésimo Almeida e, especialmente, com as idéias de Eduardo Lourenço se reveste de grande interesse. Toda essa parte caracteriza a estratégia desconstrucionista do livro.

Todavia, velhos conceitos tem no livro ainda o seu lugar. Kaufman e Ornelas, por exemplo, afirmam que a imaginação “...can be called on to complement the factual record" (p. 159), uma vez que as fronteiras entre ficção e história estão desde sempre indefinidas. Ao fazer uma afirmação como essa, os dois caem na mais positivista das posições, aquela que restringe o papel da literatura ao de ser uma fonte secundária da história. Ana Paula Ferreira, através de uma estratégia de re-generação da história, qual seja, a de reescrever a história a partir do gênero feminino, começa por desterritorializar essa mesma história, mas igualmente invoca o velho conceito de progresso a fim de realçar a retórica feminista. Não há maior contradição.

Os artigos sobre poesia e ensaio destoam da pauta geral do volume. Onésimo Almeida claramente segue o ponto de vista de Eduardo Lourenço e recusa-se a aceitar a descontinuidade entre as identidades pré e pósrevolucionárias. Fernando Martinho igualmente segue o seu próprio caminho, mas numa direção diferente. O mais pósmoderno dos críticos em todo o livro, Martinho descarta a idéia de que a revolução de 1974 tenha sido o ponto de inflexão na moderna poesia portuguesa, e mostra, com fartos exemplos, que no começo dos anos setenta a 
poesia havia já ultrapassado os conceitos modernistas de vanguarda e revolução. A poesia, àquela altura, enfatiza Martinho, já havia assumido a desilusão pósmoderna, consagrada na estética da repetição.

Kaufman e Klobucka editaram um livro complexo e muito importante. Pouco importa se o leitor gosta ou não da direção que elas deram à coletânea de ensaios. O mais importante é que o livro constitui uma leitura obrigatória, não apenas para o especialista ou o estudante de literatura portuguesa, mas igualmente para qualquer um que procure entender esses nossos tempos pós-modernos. 